\title{
Application of the technique of autologous matrix-induced chondrogenesis in the treatment of patients with osteoarthritis of the first metatarsophalangeal joint
}

\author{
M.R. Nurmukhametov ${ }^{1}$, M.A. Makarov ${ }^{1}$, E.I. Byalik ${ }^{1}$, Ya.B. Khrennikov² ${ }^{2}$ V.E. Byalik ${ }^{1}$, \\ V.A. Nesterenko ${ }^{1}$
}

${ }^{1}$ V.A. Nasonova Research Institute of Rheumatology, Moscow, Russian Federation

${ }^{2}$ Federal Scientific and Clinical Center for Specialized Types of Medical Care and Medical Technologies FMBA of Russia, Moscow, Russian Federation

\begin{abstract}
Introduction To date, there is no unified approach to the choice of tactics in surgical treatment of osteoarthritis of the first metatarsophalangeal joint (OA of the first MTP joint). On the other hand, it is known that the technique of autologous matrixinduced chondrogenesis has been successfully used for osteochondral defects in the hip, knee and ankle joints. Therefore, we have proposed to use this technique in the treatment of patients with OA of the first MTP joint. Purpose To study the possibility of surgical treatment of patients with OA of the first MTP joint with the use of chondroplasty utilizing the technique of autologous matrix-induced chondrogenesis, to demonstrate the immediate and mid-term results of such operations. Materials and methods Chondroplasty was performed in 15 patients (16 feet) with OA of the first MTP joint. The examination determined the range of motion in of the first MTP joint; the condition was assessed according to such scales as VAS for pain, AOFAS, FFI. Chondroplasty in of the first MTP joint was performed with the technique of induced chondrogenesis using a collagen matrix. The results of the operations were evaluated after 3 , 6 and 12 months. Results As early as 3 months after the operation, there was a marked significant increase in the range of motion and a decrease in pain of the first MTP joint. Moderate positive dynamics were observed after 6 and 12 months. Conclusion The results of the operations showed that chondroplasty of the first MTP joint is an effective method of surgical treatment that provides pain relief and significantly improves the quality of life of patients with OA of the first MTP joint. However, it is necessary to study long-term results. Keywords: first metatarsophalangeal joint, osteoarthritis, chondroplasty, chondrogenesis, collagen matrix
\end{abstract}

\section{INTRODUCTION}

Osteoarthritis (OA) of the first metatarsophalangeal joint (MTP joint) is a disease characterized by pain that worsens by walking, stiffness in the first MTP joint and a decrease in the range of its motion, especially dorsiflexion. OA of the first MTP joint is the second most common pathological condition of the foot after hallux valgus and occurs, according to various sources, in $2.5-10 \%$ of the adult population $[1,2]$. Currently, various methods of surgical treatment of OA of the first MTP joint have been used, such as cheilectomy, shortening osteotomies of the first metatarsal bone (MTB), hemiarthroplasty, arthroplasty and arthrodesis, and all of them have both merits and shortcomings [37]. For patients with radiological stages I and II of the disease and moderate or recurrent pain and stiffness, cheilectomy is the recommended surgical method [8]. However, it should be noted that cheilectomy does not restore the damaged areas of the articular cartilage, and therefore, pain may recur. Moreover, Canseco et al [9] in their study did not observe an increase in the volume of active movements in the first MTP joint after cheilectomy and pointed to the need to develop rehabilitation measures after surgical treatment. In turn, according to a study by Seibert et al [10], cheilectomy is contraindicated in the late stages of the disease, when less than $50 \%$ of the articular surface of the first MTP joint remains intact. Harrison et al believe that pain by the medium range of motion in the first MTP joint is associated with the presence of extensive articular cartilage defects. In such cases the effect of cheilectomy is doubtful [11]. Therefore, Coughlin and Shurnas, who developed the clinical and radiological classification of the OA of the first MTP joint, do not recommend cheilectomy in stages 3 and 4 of the disease [12]. Peace et al indicate that the main problem associated with cheilectomy is postoperative chondrolysis and recurrence of osteophytes and, as a consequence, further deformation of the articular surfaces of the first MTP joint [13]. Perler et al reported that the recurrence of dorsal osteophytes after cheilectomy occurs in $30 \%$ of patients [14].

To date, there is no unified approach to the choice of tactics for surgical treatment of OA of the first MTP joint. However, it is known that the technique of autologous matrix-induced chondrogenesis has been applied quite successfully for osteochondral defects in the knee [15, 16], hip [17, 18] and ankle [19] joints. Collagen matrices such as Chondro-Gide (Geistlich) and Aesculap Novocart Basic (BBraun) have been licensed in the Russian Federation, and the manufacturers' indications allow their use for the ankle joint. Therefore, it was suggested that these matrices could be also used in the forefoot. Therefore, we proposed this technique for treatment of patients with OA of the first MTP joint, including in the late stages of the disease [20,21]. This study was fully consistent with ethical standards and was approved by the ethics committee of the V.A. Nasonova Research Institute of Rheumatology in 2018. All patients 
were informed about the upcoming operation and signed informed consents.

Purpose To study the possibility of surgical treatment of OA of the first MTP joint with the use of chondroplasty utilizing the technique of autologous matrix-induced chondrogenesis and to demonstrate the immediate and mid-term results of such operations.

\section{MATERIALS AND METHODS}

To date, chondroplasty using the technique of induced chondrogenesis was performed at V.A. Nasonova Research Institute of Rheumatology in 15 patients with OA of the first MTP joint. Ten patients were females and five males. One patient underwent surgery on both feet; thus, a total of 16 operations were performed. The recruitment of patients into the study was carried out taking into account the following exclusion criteria: age under 18 and over 74 years old, body mass index $>40$, presence of systemic diseases of moderate and high activity, and infectious diseases. The median age of patients was 55 years old (range, 20 to 71 years). To assess the condition of patients before surgery, the range of motion in the first MTP joint was evaluated, and the following questionnaires were also used:

1) Visual analogue scale (VAS) for pain ( 0 - no pain, $100 \mathrm{~mm}$ - maximum pain);

2) American Orthopedic Foot \& Ankle Society (AOFAS) score from 0 to 100 points, where 0 is the worst condition of the foot, 100 is the best [22];

3) The functional index of the foot (Foot Function Index - FFI), from 0 to 10 , where 0 is the best index, 10 is the worst one [23].

Due to a small sample size, it was decided that for each of the estimated parameters, instead of the mean, it was more expedient to calculate the median.

Table 1 presents the clinical parameters of patients before surgery. All patients experienced significant limitation of movements in the first MTP joint before surgery. The minimum range of motion was $15^{\circ}$, the maximum was $50^{\circ}$, and the median was $20^{\circ}$. The

median of pain according to VAS was $70 \mathrm{~mm}$ (minimum pain level $-40 \mathrm{~mm}$, maximum $-90 \mathrm{~mm}$ ), while the median AOFAS score was 52 (minimum score - 39, maximum -62). The median FFI before surgery was 6.1 (minimum-2.1, maximum - 8.2) (Table 1, Fig. 6-9).

To assess the clinical and radiographic parameters before surgery, the above-mentioned CoughlinShurnas classification was used (Table 2) [12]. This classification includes five stages of the disease (from 0 to 4 ) and such characteristics as the state of the joint space of the first MTP joint, the nature of pain and limitation of the range of motion in the joint.

Table1

Clinical parameters before the operation

\begin{tabular}{|c|c|c|c|c|c|}
\hline & $\begin{array}{l}\text { Age, } \\
\text { years }\end{array}$ & $\begin{array}{l}\text { VAS } \\
\text { for pain, } \\
\text { mm }\end{array}$ & $\begin{array}{c}\text { AOFAS } \\
\text { score }\end{array}$ & FFI & $\begin{array}{l}\text { Range of motion } \\
\text { in } 1^{\text {st }} \text { MTP joint, } \\
\text { degrees }\end{array}$ \\
\hline 1. & 22 & 80 & 52 & 6.9 & 20 \\
\hline 2. & 27 & 70 & 55 & 6.2 & 25 \\
\hline 3. & 25 & 90 & 52 & 7 & 20 \\
\hline 4. & 40 & 80 & 39 & 7.6 & 15 \\
\hline 5. & 70 & 70 & 52 & 6.5 & 30 \\
\hline 6. & 58 & 60 & 54 & 4.3 & 30 \\
\hline 7. & 71 & 70 & 52 & 6.5 & 15 \\
\hline 8. & 37 & 50 & 62 & 3.7 & 20 \\
\hline 9. & 52 & 50 & 47 & 2.7 & 20 \\
\hline 10. & 20 & 90 & 44 & 6.3 & 15 \\
\hline 11. & 63 & 80 & 52 & 5.8 & 20 \\
\hline 12. & 66 & 90 & 52 & 8.2 & 15 \\
\hline 13. & 59 & 70 & 39 & 5.9 & 15 \\
\hline 14. & 66 & 40 & 55 & 2.1 & 20 \\
\hline 15. & 59 & 60 & 45 & 4.4 & 50 \\
\hline 16. & 52 & 50 & 52 & 3.2 & 40 \\
\hline Median & 55 & 70 & 52 & 6.1 & 20 \\
\hline
\end{tabular}

Table 2

Clinical and radiographic Coughlin-Shurnas classification of OA of the first MTP joint

\begin{tabular}{|c|c|c|c|}
\hline Stage & Dorsiflexion & Radiographic signs & Clinical signs \\
\hline 0 & $\begin{array}{l}40^{\circ} \text { to } 60^{\circ} \text { and / or } \\
10 \text { to } 20 \% \text { loss of volume } \\
\text { compared to a healthy foot }\end{array}$ & Normal & $\begin{array}{l}\text { No pain, slight restriction of } \\
\text { motions }\end{array}$ \\
\hline 1 & $\begin{array}{l}30^{\circ} \text { to } 40^{\circ} \text { and / or } \\
20 \text { to } 50 \% \text { loss of volume } \\
\text { compared to a healthy foot }\end{array}$ & $\begin{array}{l}\text { Dorsal osteophyte on the head of the } 1^{\text {st }} \text { MTB, minimal } \\
\text { narrowing of the joint space, minimal periarticular sclerosis, } \\
\text { minimal flattening of the head of the } 1 \text { st MTB }\end{array}$ & $\begin{array}{l}\text { Minor or occasional pain by } \\
\text { examination, pain occurs at the } \\
\text { extreme point of dorsal and / or } \\
\text { plantar flexion }\end{array}$ \\
\hline 2 & $\begin{array}{l}10^{\circ} \text { to } 30^{\circ} \text { and / or } 50 \\
\text { to } 75 \% \text { loss of volume } \\
\text { compared to a healthy foot }\end{array}$ & $\begin{array}{l}\text { Dorsal, lateral and, possibly, medial osteophytes, creating a } \\
\text { picture of flattening of the head of the } 1^{\text {st }} \text { MTB; in the lateral view } \\
\text { - involvement in the pathological process of no more than } 1 / 4 \text { of } \\
\text { the joint space from the dorsal side; narrowing of the joint space, } \\
\text { sclerosis of the articular surfaces - from mild to moderate; sesamoid } \\
\text { bones, as a rule, are not involved in the pathological process }\end{array}$ & $\begin{array}{l}\text { Moderate to severe pain and } \\
\text { stiffness that may be persistent; } \\
\text { by examination, pain occurs } \\
\text { up to the maximum points of } \\
\text { dorsal and plantar flexion }\end{array}$ \\
\hline 3 & $\begin{array}{l}\leq 10^{\circ} \text { and / or } 75 \text { to } 100 \% \\
\text { loss of volume compared to } \\
\text { a healthy foot. There is also } \\
\text { a significant limitation of } \\
\text { plantar flexion (usually, } \leq 10^{\circ} \text { ) }\end{array}$ & $\begin{array}{l}\text { Pronounced narrowing of the joint space, possible } \\
\text { periarticular cystic enlightenments, involvement of more } \\
\text { than } 1 / 4 \text { of the joint space from the dorsal side, as well as of } \\
\text { sesamoid bones in the pathological process }\end{array}$ & $\begin{array}{l}\text { Almost constant pain and } \\
\text { severe stiffness at the extreme } \\
\text { points of the range of motion, } \\
\text { but not at the middle level }\end{array}$ \\
\hline 4 & Same as for stage 3 & Same as in stage 3 & $\begin{array}{l}\text { Same as in stage } 3 \text {, but there is } \\
\text { pain in the middle range of motion }\end{array}$ \\
\hline
\end{tabular}


According to the Coughlin and Shurnas classification, two patients had OA stage 2 of the first MTP joint, nine patients (one patient with bilateral involvement) had stage 3 , and four patients had stage 4 of the disease.

The presence and size of the defect in the cartilaginous covering of the head of the $1^{\text {st }}$ MTB was determined intraoperatively. Solitary defects of cartilage with a diameter of more than $3 \mathrm{~mm}$ (Fig. 1), as well as multiple defects, regardless of size, were subjected to plasty. In most cases (11 operations), multiple cartilage defects were found in combination with osteophytes (Fig. 2), thereby, total cheilectomy was performed with the entire area of the head of the $1^{\text {st }}$ MTB was covered by a collagen matrix.

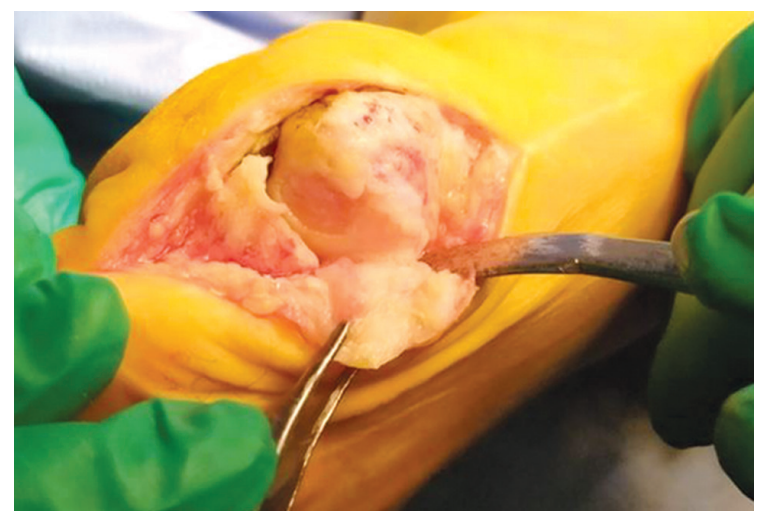

Fig. 1 Solitary defect in the cartilage with a diameter of more than $3 \mathrm{~mm}$

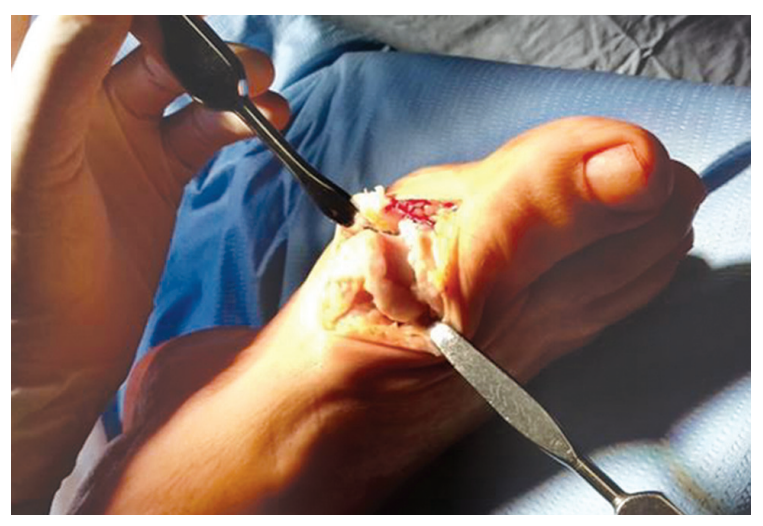

Fig. 2 Multiple osteophytes and cartilage defects

Chondroplasty of the $1^{\text {st }}$ MTP joint was performed according to the technique of autologous matrixinduced chondrogenesis using the Chondro-Gide and Aesculap Novocart Basic collagen matrices. The matrix is composed of collagens type I and type III. It has a two-layer structure with dense and porous sides. The dense layer has a smooth surface impermeable to cells, which prevents the penetration of mesenchymal stem cells into the joint cavity. The porous layer consists of loose collagen fibers that promote cell adsorption. The matrix is fabricated from porcine collagen; some time after the operation, it is naturally resorbed by enzymes to free amino acids. During the manufacturing process, telopeptides, the main determinants of antigenicity, are removed from collagen. Thus, the collagen matrix has a minimal immunogenic potential $[15,16]$.

The operation was performed as follows. A 4-cm long direct medial skin incision in the projection of the first MTP joint was performed, followed by mobilization of the skin with subcutaneous fat, exposure of the joint capsule and arthrotomy. Removal of osteophytes from the head of the $1^{\text {st }}$ MTB and the base of the proximal phalanx of the first toe - cheilectomy; the area of the cartilage defect on the head of the metatarsal bone was processed to the subchondral bone (Fig. 3); microfracturing (Fig. 4) of this area was performed using a thin needle or awl (distance between the microperforations was $2-3 \mathrm{~mm}$ ), and the defect was covered with a previously prepared two-layer collagen matrix, which was fixed along the edges to the intact cartilage and / or periosteum using thin absorbable sutures, such as PDS, Vicryl or Monosyn 6-0 (Fig. 5). It is important to pay attention to the fact that the matrix was applied to the defect with a porous layer to the bone surface.

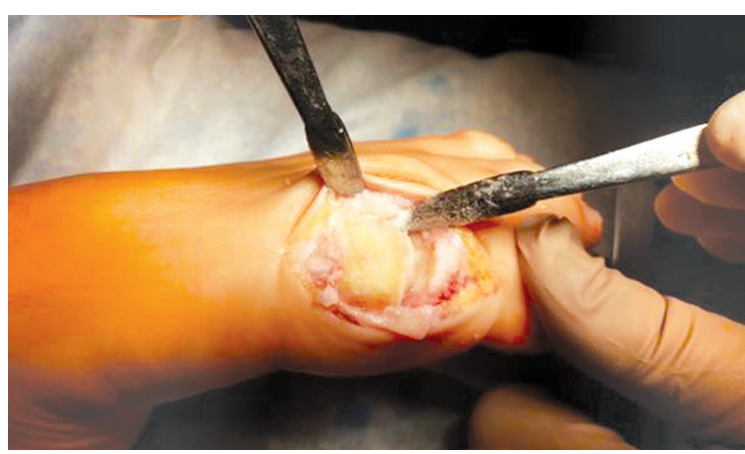

Fig. 3 Cheilectomy, removal of the remnants of damaged cartilage

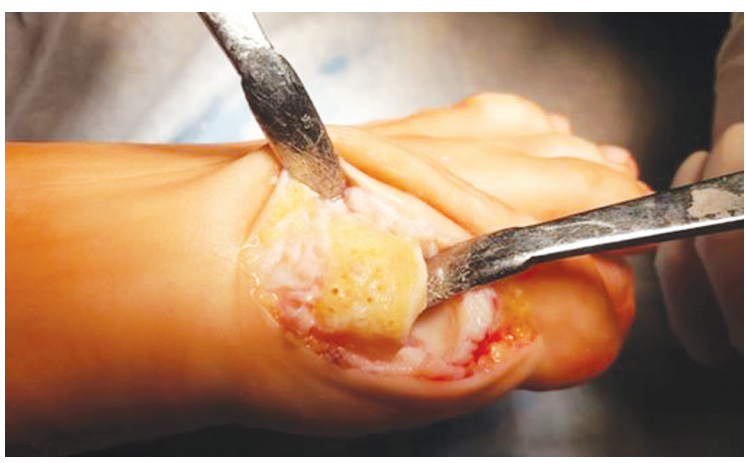

Fig. 4 Microfracturing of the defect zone

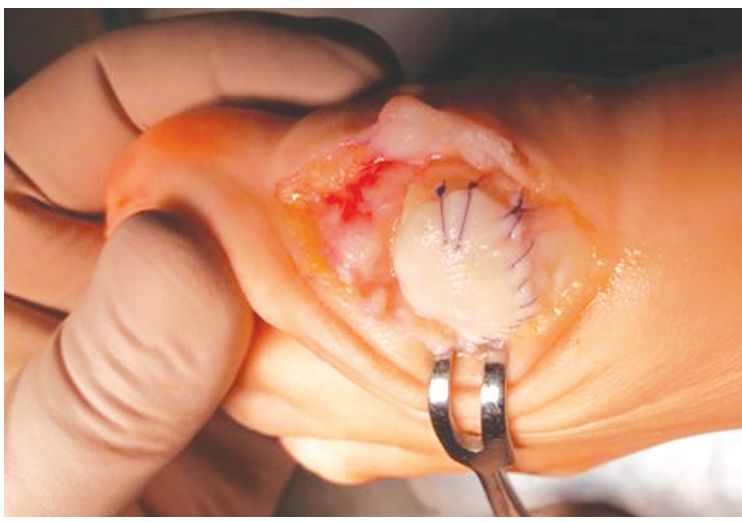

Fig. 5 Placement and fixation of the collagen matrix with thin absorbable filaments 
Before application, the collagen matrix was kept in $0.9 \% \mathrm{NaCl}$ solution for 7 minutes, and then the matrix was trimmed along the edge of the defect.

In the postoperative period, the patients were verticalized the next day after the operation. According to the technique of induced chondrogenesis, axial load on the operated joint should be excluded for 4-6 weeks after surgery $[15,18]$. Therefore, a prerequisite for postoperative rehabilitation in our patients was wearing Baruk's shoes to unload the forefoot for 6 weeks. With regard to movements after chondroplasty of large joints using the technique of matrix-induced chondrogenesis, it is recommended to exclude movements in the operated joint for two postoperative weeks, and then to begin gradual training $[15,18]$. On the other hand, after cheilectomy, a number of authors, in particular, Seibert et al, point to the need for early aggressive training of movements in the first MTP joint [10]. Based on this, we recommended that our patients start gradual training of passive movements in a painless range one week after surgery. It was recommended to start active movements three weeks after the operation. After switching to normal shoes, patients were advised to use individual insoles.

The results of the surgical treatment were assessed using the above questionnaires at follow-ups of 3, 6 and 12 months after the operation.

The Wilcoxon test (W) was used as a statistical test, the essence of which is that the absolute values of the severity of shifts in one direction or another are compared [24, 25]. Consequently, the greater is the magnitude of the severity of the shift, the less the likelihood of random shifts. If the shift goes down, the criterion $\mathrm{W}$ acquires a positive value $(+)$; if the shift goes up, the criterion $\mathrm{W}$ acquires a negative value (-).

This test was chosen due to the small sample size (minimum number of subjects is 5, the maximum is 50).

Statistical calculations of the Wilcoxon test, as well as the level of statistical significance (p), were performed using the BioStat ${ }^{\circledR}$ software.

\section{RESULTS}

The dynamics of the pain according to the VAS is shown in Figure 6. It shows that by the third month there was a pronounced significant decrease in pain from 70 to $27.5 \mathrm{~mm}$ (minimum value was $10 \mathrm{~mm}$, the maximum value was $40 \mathrm{~mm}$; $\mathrm{p}<0.024, \mathrm{~W}=36.0$ ). Positive dynamics was also observed after 6 months, as the level of pain according to the VAS was $10 \mathrm{~mm}$ (minimum value $-0 \mathrm{~mm}$, maximum $-40 \mathrm{~mm}$; $\mathrm{p}<0.024, \mathrm{~W}=36.0$ ). By the end of the first year of follow-up, the median pain according to the VAS remained at the same level of $10 \mathrm{~mm}$ (minimum value $-0 \mathrm{~mm}$, maximum $-40 \mathrm{~mm} ; \mathrm{p}<0.024$, $\mathrm{W}=36.0)$.

Figure 7 shows the dynamics of the AOFAS score. As shown, by the third month after surgery, the median AOFAS increased from 52 to 78.5 (minimum score67 , maximum -85 (the presence of a minimum level of pain and limitation of range of motion less than $\left.\left.75^{\circ}\right) ; \mathrm{p}<0.024, \mathrm{~W}=-36.0\right)$. After 6 months, positive dynamics continued as the median AOFAS score grew to 90 (minimum score -67 , maximum $-95 ; \mathrm{p}<0.024$,

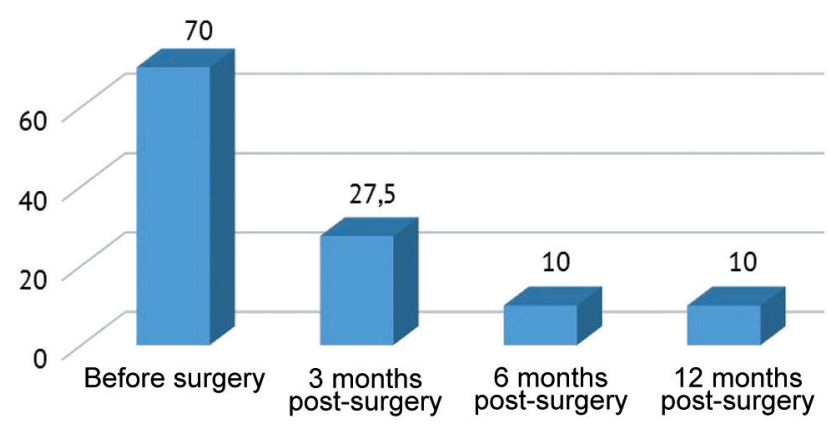

Fig. 6 Dynamics of VAS pain levels
$\mathrm{W}=-36.0$ ), and after 12 months it was also 90 (minimum score -67 , maximum $-95 ; \mathrm{p}<0.024, \mathrm{~W}=-36.0$ ).

The dynamics of the FFI index is shown in Figure 8. Three months after the performed chondroplasty, the median of the index decreased from 6.1 to 2.3 (minimum index -1.1 , maximum $-4.7 ; \mathrm{p}<0.024$, $\mathrm{W}=36.0$ ). After 6 months, the FFI index continued to decrease to 1.1 (the minimum index was 0.5 , the maximum was $3.9 ; \mathrm{p}<0.024, \mathrm{~W}=36.0$ ), and after 12 months the index stabilized at 1.1 ( the minimum index is 0 , the maximum is $2.7 ; \mathrm{p}<0.024, \mathrm{~W}=36.0$ ).

As for the range of motion in the 1st MTP joint (Fig. 9 to Fig. 11), a significant increase was also observed after three months post-surgery, as the median range of motion increased from $20^{\circ}$ to $60^{\circ}$ (the minimum value is $30^{\circ}$, the maximum is $70^{\circ}, \mathrm{p}<0.024, \mathrm{~W}=-36.0$ ). After 6 months, positive dynamics persisted with the median range of motion of $65^{\circ}$ (minimum value $-30^{\circ}$, maximum $\left.-80^{\circ}, \mathrm{p}<0.024, \mathrm{~W}=-36.0\right)$, and after a year of observation it increased to $67.5^{\circ}$ (minimum value $40^{\circ}$, maximum $-90^{\circ}, \mathrm{p}<0.024, \mathrm{~W}=-36.0$ ).

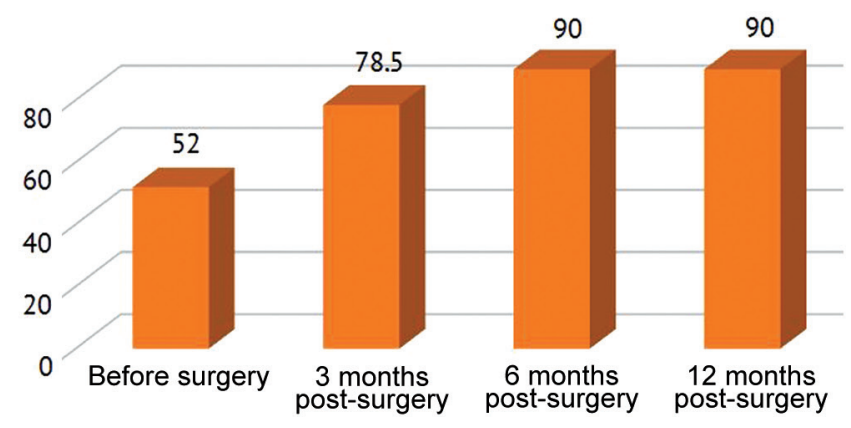

Fig. 7 Dynamics of the AOFAS indicators 


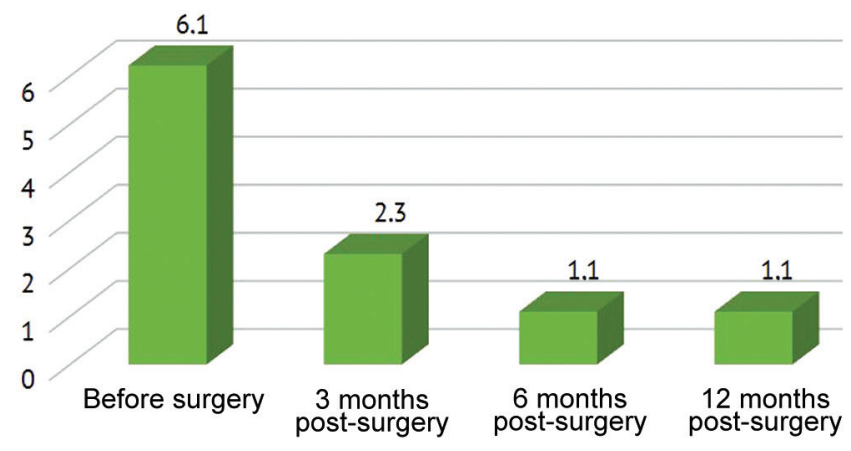

Fig. 8 Dynamics of the FFI index
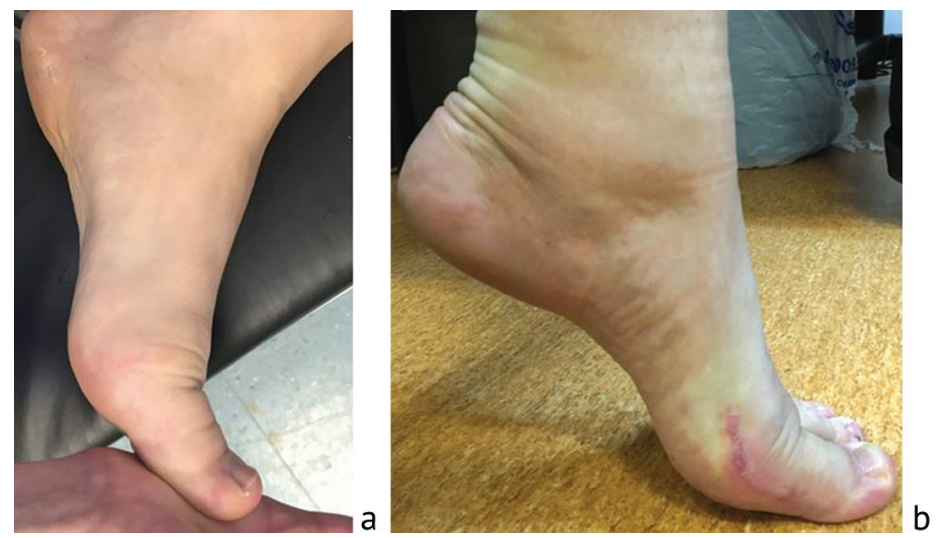

Fig. 10 Dorsiflexion in the $1^{\text {st }}$ MTP joint: $\boldsymbol{a}$ before surgery - 300; b 3 months. after surgery -550 (patient P., 52 years old; VAS pain before surgery $-50 \mathrm{~mm}$, after 3 months $-20 \mathrm{~mm}$; AOFAS before surgery -52 , after 3 months -63 )

Postoperative X-ray of the feet showed a significant increase in the joint space of the $1^{\text {st }}$ MTP joint (Fig. 12). However, at follow-ups after 3, 6, and 12 months, narrowing of the joint space was observed. However, clinically, this phenomenon was not manifested by a decrease in the range of motion. On the contrary, in general, patients noted an increase
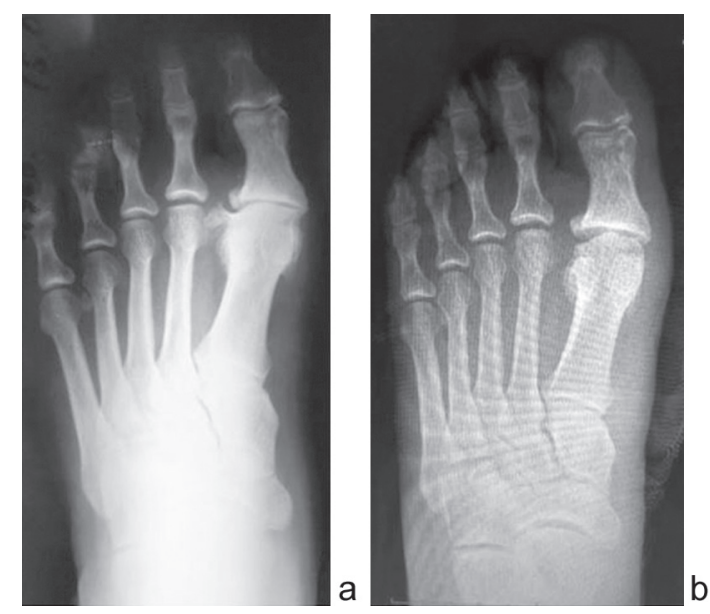

Fig. 12 Radiographs of the foot: $\boldsymbol{a}$ before surgery; $\boldsymbol{b}$ on the first day after surgery

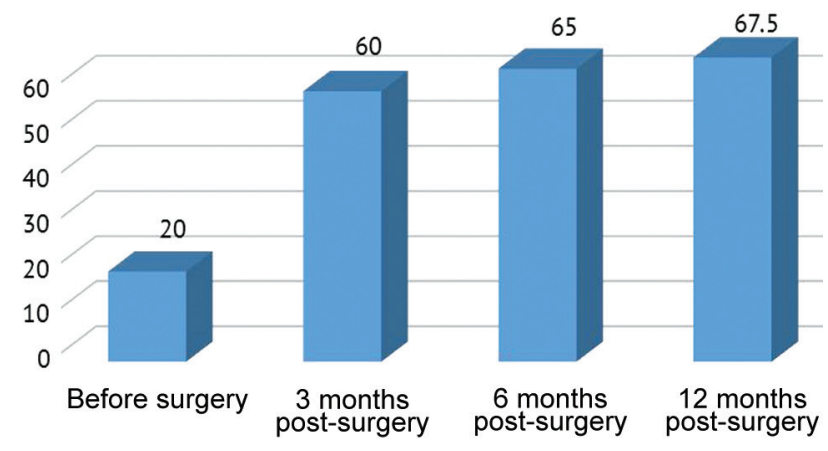

Fig. 9 Dynamics of the range of motion in the $1^{\text {st }}$ MTP joint

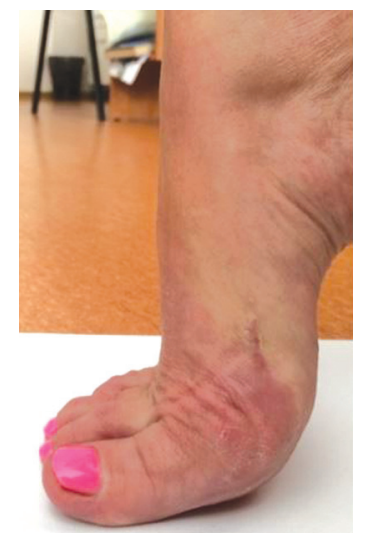

Fig. 11 Dorsiflexion in the $1^{\text {st }}$ MTP joint 6 months after surgery $-80^{\circ}$ (patient Sh., 58 years old; dorsiflexion before surgery $-30^{\circ}$, VAS pain before surgery $-60 \mathrm{~mm}$, after 12 months $-0 \mathrm{~mm}$; AOFAS before surgery $-52,12$ months after -95 )

in the range of motion in the $1^{\text {st }}$ MTP joint from the $3^{\text {rd }}$ to the $12^{\text {th }}$ month after the surgery (Fig. 9).

Of particular interest is the MRI image after surgery. In the area of the head of the $1^{\text {st }}$ MTB, botryoid-like formations, "artifacts", are seen (Fig. 13). Most likely, this is how the formed hyalinelike tissue looks on MRI.

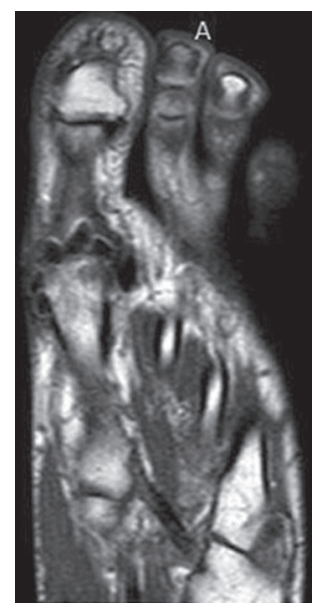

Fig. 13 MRI of the foot 12 months post-surgery (patient D., 40 years old)

\section{DISCUSSION}

The problems of surgical treatment of OA of the first MTP joint have been studied for more than a dozen years. Disease classifications have been developed, and many surgical methods have been described. Such techniques as shortening osteotomy of the first MT bone [26, 27], cheilectomy or, in advanced stages, arthrodesis of 
the first MTP joint [28-30] have been used and have proven, in general, their positive effects. However, these methods are not without certain shortcomings. In particular, excessive shortening of the first MT bone is frequent after osteotomy and leads to metatarsalgia due to overload [31]. With all the advantages of arthrodesis in achieving a complete pain relief, the main shortcoming of this method is the lack of movements in the first MTP joint and, as a consequence, biomechanical disorders of the foot by walking $[32,33]$. Cheilectomy is ineffective in the advanced stages of the disease [10]. Chondroplasty has been used, including for disease stages 3 and 4 . Moreover, in contrast to induced chondrogenesis, cheilectomy does not restore cartilaginous tissue of the first MTP joint. Despite the constant improvement of the technology for manufacturing endoprostheses for hemiarthroplasty and arthroplasty of the first MTP joint, the risk of developing aseptic instability remains high, and this method cannot be recommended as the method of choice [1,34]. Thus, the problem of surgical treatment of OA of the first MTP joint has not been resolved yet.

Only one study, conducted in 2016, proposes a similar method of surgical treatment for OA of the first MTP joint to the one used in our study, a modified version of induced chondrogenesis called MAST (matrix-associated stem cell transplantation) [35]. M. Richter followed up the patients $(n=20)$ for two years after the chondroplasty of the first MTP joint and observed a significant improvement in clinical parameters both in the early postoperative period and after the mentioned period of follow-up (including an increase in range of motion in the first MTP joint). The range of motion increased from $29.1^{\circ}$ to $60^{\circ}$.

Erdil M. et al compared the efficacy of arthroplasty (group A), hemiarthroplasty (group B) and arthrodesis (group C) of the first MTP joint [5]. They followed up their patients $(n=38)$ for 24-66 months. In group A, the level of pain according to the VAS decreased from 76.7 to $15.8 \mathrm{~mm}$, the AOFAS score increased from 45.4 to 92.7, the range of motion in the first MTP joint increased from $15.1^{\circ}$ to $40^{\circ}$. In group B, pain according to VAS decreased from 78.6 to $13.6 \mathrm{~mm}$, the AOFAS score increased from 38.4 to 86.1 , the range of motion in the first MTP joint increased from $20.5^{\circ}$ to $47.9^{\circ}$. Group C showed a decrease in the VAS pain from 80 to $5 \mathrm{~mm}$ and an increase in AOFAS score from 33.6 to 76.1. The range of motion due to arthrodesis of the first MTP joint in this group of patients decreased from $13.3^{\circ}$ to $0^{\circ}$.

Coughlin and Shurnas, in turn, analyzed long-term results after cheilectomy of the first MTP joint (mean follow-up was 9.6 years). In their study, the level of pain according to VAS decreased from 80 to $15 \mathrm{~mm}$, the AOFAS score increased from 45 to 90 , the range of motion in the first MTP joint increased from $39.2^{\circ}$ to $63.7^{\circ}$ [12].

In our study, by the 12th month of observation, the range of motion in the first MTP joint increased from $20^{\circ}$ to $71.5^{\circ}$; pain decreased from 70 to $5 \mathrm{~mm}$ according to VAS, and the AOFAS score increased from 52 to 92.5 . Compared to the above studies, the results we obtained are better; however, unlike other studies, we currently have insufficient data on long-term results.

A particularly significant difference in the indicators before and after surgery is observed in the early period, after three months: the level of pain according to VAS decreases by an average of $42.5 \mathrm{~mm}$, AOFAS score increases by 26.5 , FFI by 2.1. It should be noted that the difference in indicators is statistically significant $(\mathrm{p}<0.024)$.

Asignificant improvement in the condition of patients in the early postoperative period may be associated with wearing of Baruk's postoperative shoes which provide unloading of the forefoot. However, patients use these shoes only for 6 weeks after the operation; and, nevertheless, the positive dynamics was observed for 6 months after the operation. There was further decrease in pain according to VAS by $17.5 \mathrm{~mm}$, an increase in AOFAS by 12.5 , and FFI by 1.2 . The difference in indicators is also statistically significant $(p<0.024)$.

Later, after 12 months of observation, the condition of the patients, in general, stabilizes at a positive level.

\section{CONCLUSION}

The short- and mid-term results of the operations showed that chondroplasty of the first MTP joint using a collagen matrix is a rather effective method of surgical treatment that provides pain relief and significantly improves the quality of life of patients suffering from OA of the first MTP joint. Patients have a significant positive dynamics three months after the operation, and within a year the condition stabilizes at a good level. The study of long-term results of the operations will give a more complete assessment of the efficacy of chondroplasty of the first MTP joint using the technique of autologous matrix-induced chondrogenesis.

\section{REFERENCES}

1. Berezhnoi S.Iu. Artrozpervogo pliusnefalangovogo sustava: chreskozhnoe operativnoe lechenie, vybor khirurgicheskoi metodiki, kliniko-rentgenologicheskaia klassifikatsiia [Arthrosis of the first metatarsophalangeal joint: percutaneous surgical treatment, choice of surgical technique, clinical and roentgenological classification]. Travmatologiia i Ortopediia Rossii, 2017, vol. 23, no. 1, pp. 8-22. (in Russian) DOI: 10.21823/2311-2905-2017-23-1-8-22

2. McNeil D.S., Baumhauer J.F., Glazebrook M.A. Evidence-based analysis of the efficacy for operative treatment of hallux rigidus. Foot Ankle Int., 2013, vol. 34, no. 1, pp. 15-32. DOI: $10.1177 / 1071100712460220$

3. Sorbie C., Saunders G.A. Hemiarthroplasty in the treatment of hallux rigidus. Foot Ankle Int., 2008, vol. 29, no. 3, pp. 273-281. DOI: 10.3113/ FAI.2008.0273

4. Mackey R.B., Thomson A.B., Kwon O., Mueller M.J., Johnson J.E. The modified oblique Keller capsular interpositional arthroplasty for hallux rigidus. J. Bone Joint Surg. Am., 2010, vol. 92, no. 10, pp. 1938-1946. DOI: 10.2106/JBJS.I.00412 
5. Erdil M., Elmadag N.M., Polat G., Tunçer N., Bilsel K., Uçan V., Erkoçak O.F., Sen C. Comparison of Arthrodesis, Resurfacing Hemiarthroplasty, and Total Joint Replacement in the Treatment of Advanced Hallux Rigidus. J. Foot Ankle Surg., 2013, vol. 52, pp. 588-593. DOI: 10.1053/j.jfas.2013.03.014

6. Calvo A., Viladot R., Giné J., Alvarez F. The importance of the length of the first metatarsal and the proximal phalanx of hallux in the etiopathogeny of the hallux rigidus. Foot Ankle Surg., 2009, vol. 15, no. 2, pp. 69-74. DOI: 10.1016/j.fas.2008.08.001.

7. Keiserman L., Sammarco J., Sammarco G.J. Surgical treatment of the hallux rigidus. Foot Ankle Clin. N. Am., 2005, vol. 10, pp. 75-96. DOI: 10.1016/j. fcl.2004.09.005

8. Waizy H., Czardybon M.A., Stukenborg-Colsman C., Wingenfeld C., Wellmann M., Windhagen H., Frank D. Mid- and long-term results of the joint preserving therapy of hallux rigidus. Arch. Orthop. Trauma Surg., 2010, vol. 130, no. 2, pp. 165-170. DOI: 10.1007/s00402-009-0857-1

9. Canseco K., Long J., Marks R., Khazzam M.S., Harris G. Quantitative motion analysis in patients with hallux rigidus before and after cheilectomy. J. Orthop. Res., 2009, vol. 27, no. 1, pp. 128-134. DOI: 10.1002/jor.20711

10. Seibert N.R., Kadakia A.R. Surgical management of hallux rigidus: cheilectomy and osteotomy (phalanx and metatarsal). Foot Ankle Clin., 2009, vol. 14, no. 1, pp. 9-22. DOI: 10.1016/j.fcl.2008.11.002

11. Harrison T., Fawzy E., Dinah F., Palmer S.H. Prospective Assessment of Dorsal Cheilectomy for Hallux Rigidus Using a Patient-reported Outcome Score. J. Foot Ankle Surg., 2010, vol. 49, no. 3, pp. 232-237. DOI: 10.1053/j.jfas.2010.02.004

12. Coughlin M.J., Shurnas P.S. Hallux rigidus. Grading and long-term results of operative treatment. J. Bone Joint Surg. Am., 2003, vol. 85, no. 11, pp. 2072-2088. DOI: 10.2106/00004623-200311000-00003

13. Peace R.A., Hamilton G.A. End-Stage Hallux Rigidus. Clin. Podiatr. Med. Surg., 2012, vol. 29, no. 3, pp. 341-353. DOI: 10.1016/j.cpm.2012.04.002

14. Perler A.D., Nwosu V., Christie D., Higgins K. End-stage osteoarthritis of the great toe/hallux rigidus: a review of the alternatives to arthrodesis: implant versus osteotomies and arthroplasty techniques. Clin. Podiatr. Med. Surg., 2013, vol. 30, no. 3, pp. 351-395, DOI: 10.1016/j.cpm.2013.04.011

15. Benthien J.P., Behrens P. Autologous matrix-induced chondrogenesis (AMIC): combining microfracturing and a collagen I/III matrix for articular cartilage resurfacing. Cartilage, 2010, vol. 1, no. 1, pp. 65-68. DOI: 10.1177/1947603509360044

16. Gille J., Behrens P., Volpi P., De Girolamo L., Reiss E., Zoch W., Anders S. Outcome of Autologous Matrix Induced Chondrogenesis (AMIC) in cartilage knee surgery: data of the AMIC Registry. Arch. Orthop. Trauma Surg., 2013, vol. 133, no. 1, pp. 87-93. DOI: 10.1007/s00402-012-1621-5

17. Jannelli E., Fontana A. Arthroscopic treatment of chondral defects in the hip: AMIC, MACI, microfragmented adipose tissue transplantation (MATT) and other options. SICOT J., 2017, vol. 3, pp. 43. DOI: 10.1051/sicotj/2017029

18. Usuelli F.G., D’Ambrosi R., Maccario C., Boga M., De Girolamo L. All-arthroscopic AMIC® (AT-AMIC®) technique with autologous bone graft for talar osteochondral defects: clinical and radiological results. Knee Surg. Sports Traumatol. Arthrosc., 2018, vol. 26, no. 3, pp. 875-881. DOI: $10.1007 / \mathrm{s} 00167-016-4318-4$

19. Fontana A., De Girolamo L. Sustained five-year benefit of autologous matrix-induced chondrogenesis for femoral acetabular impingement-induced chondral lesions compared with microfracture treatment. Bone Joint J., 2015, vol. 97-B, no. 5, pp. 628-635. DOI: 10.1302/0301-620X.97B5.35076

20. Nurmukhametov M.R., Makarov M.A., Bialik E.I., Bialik V.E., Nesterenko V.A. Ispolzovanie khondroplastiki i pliusnefalangovogo sustava po tekhnike autologichnogo indutsirovannogo matritsei khondrogeneza dlia lecheniia patsientov s hallux rigidus: blizhaishie rezultaty [The use of chondroplasty of the first metatarsophalangeal joint according to the technique of autologous matrix-induced chondrogenesis for the treatment of patients with hallux rigidus: short-term results]. Nauchno-Prakticheskaia Revmatologiia, 2020, vol. 58, no. 1, pp. 97-101. (in Russian) DOI: 10.14412/1995-4484-2020-97-101

21. Nurmukhametov M.R., Makarov M.A., Makarov S.A., Bialik E.I., Khrennikov Ia.B., Bialik V.E., Nesterenko V.A. Khondroplastika po tekhnike autologichnogo indutsirovannogo matritsei khondrogeneza (AMIC) kak novyi metod khirurgicheskogo lecheniia patsientov s hallux rigidus. Blizhaishie i srednesrochnye rezultaty [Chondroplasty according to the technique of autologous matrix-induced chondrogenesis (AMIC) as a new method of surgical treatment of patients with hallux rigidus. Short-term and med-term results]. III Mezhdunarodnyi Kongress Assotsiatsii Revmoortopedov: tez. dokl. [Proceedings of the III International Congress of the Association of Rheumoorthopedists]. Voronezh, Nauchnaia Kniga, 2019, pp. 85-87. (in Russian)

22. Kitaoka H.B., Alexander I.J., Adelaar R.S., Nunley J.A., Myerson M.S., Sanders M. Clinical rating systems for the ankle-hindfoot, midfoot, hallux and lesser toes. Foot Ankle Int., 1994, vol. 15, no. 7, pp. 349-353. DOI: 10.1177/107110079401500701

23. Budiman-Mak E., Conrad K.J., Roach K.E. The Foot Function Index: a measure of foot pain and disability. J. Clin. Epidemiol., 1991, vol. 44, no. 6, pp. 561-570. DOI: 10.1016/0895-4356(91)90220-4

24. Pratt J. Remarks on Zeros and Ties in the Wilcoxon Signed Rank Procedures. Journal of the American Statistical Association, 1959, vol. 54, no. 287, pp. 655-667. DOI: $10.2307 / 2282543$

25. Sidorenko E.V. Metody matematicheskoi obrabotki v psikhologii [Methods of mathematical processing in psychology]. SPb., Rech, 2000,350 p. (in Russian)

26. Derner R., Goss K., Postowski H.N., Parsley N. A plantar-flexor-shortening osteotomy for hallux rigidus: a retrospective analysis. J. Foot Ankle Surg., 2005, vol. 44, no. 5, pp. 377-389. DOI: 10.1053/j.jfas.2005.07.010

27. Freeman B.L., Hardy M.A. Multiplanar phalangeal and metatarsal osteotomies for hallux rigidus. Clin. Podiatr. Med. Surg., 2011, vol. 28, no. 2, pp. 329-344. DOI: 10.1016/j.cpm.2011.03.002

28. Goucher N.R., Coughlin M.J. Hallux metatarsophalangeal joint arthrodesis using dome-shaped reamers and dorsal plate fixation: a prospective study. Foot Ankle Int., 2006, vol. 27, no. 11, pp. 869-876. DOI: 10.1177/107110070602701101

29. Bennett G.L., Sabetta J. First metatarsal phalangeal joint arthrodesis: evaluation of plate and screw fixation. Foot Ankle Int., 2009, vol. 30, no. 8 , pp. 752-757. DOI: 10.3113/ FAI.2009.0752

30. Ellington J.K., Jones C.P., Cohen B.E., Davis W.H., Nickisch F., Anderson R.B. Review of 107 hallux MTP joint arthrodesis using dome-shaped reamers and a stainless-steel dorsal plate. Foot Ankle Int., 2010, vol. 31, no. 5, pp. 385-390. DOI: 10.3113/FAI.2010.0385

31. Bobrov D.S., Sliniakov L.Iu., Sukhareva A.G., Kholodaev M.Iu., Iakimov L.A. Khirurgicheskoe lechenie peregruzochnoi metatarzalgii [Surgical treatment of overload metatarsalgia]. Moskovskii Khirurgicheskii Zhurnal, 2014, no. 3 (37), pp. 25-27. (in Russian)

32. Van Doeselaar D.J., Heesterbeek P.J., Louwerens J.W., Swierstra B.A. Foot function after fusion of the first metatarsophalangeal joint. Foot Ankle Int., 2010, vol. 31, no. 8, pp. 670-675. DOI: 10.3113/FAI.2010.0670

33. DeFrino P.F., Brodsky J.W., Pollo F.E., Crenshaw S.J., Beischer A.D. First metatarsophalangeal arthrodesis: a clinical, pedobarographic and gait analysis study. Foot Ankle Int., 2002, vol. 23, no. 6, pp. 496-502. DOI: 10.1177/107110070202300605.

34. Polzer H., Polzer S., Brumann M., Mutschler W., Regauer M. Hallux rigidus: joint preserving alternatives to arthrodesis - a review of the literature. World J. Orthop., 2014, vol. 5, no. 1, pp. 6-13. DOI: 10.5312/wjo.v5.i1.6

35. Richter M., Zech S., Andreas Meissner S. Matrix-associated stem cell transplantation (MAST) in chondral defects of the 1st metatarsophalangeal joint is safe and effective - 2-year-follow-up in 20 patients. Foot Ankle Surg., 2017, vol. 23, no. 3, pp. 195-200. DOI: 10.1016/j.fas.2016.05.318

Received: 16.07 .2020

\section{Information about the authors:}

1. Maxim R. Nurmukhametov, M.D.,

V.A. Nasonova Research Institute of Rheumatology, Moscow, Russian Federation, Email: nurmi91@mail.ru

2. Maxim A. Makarov, M.D., Ph.D.

V.A. Nasonova Research Institute of Rheumatology, Moscow, Russian Federation, Email: ortopedniir@mail.ru

3. Evgeny I. Byalik, M.D., Ph.D., Professor,

V.A. Nasonova Research Institute of Rheumatology, Moscow, Russian Federation

4. Yaroslav B. Khrennikov, M.D., Ph.D.,

FSCC for Specialized Types of Medical Care and Medical Technologies FMBA of Russia, Moscow, Russian Federation,

Email: yaroslav79@yandex.ru

5. Valery E. Byalik, M.D.,

V.A. Nasonova Research Institute of Rheumatology, Moscow, Russian Federation,

Email: nervus11@yandex.ru

6. Vadim A. Nesterenko, M.D.,

V.A. Nasonova Research Institute of Rheumatology, Moscow, Russian Federation,

Email: swimguy91@mail.ru 